The British Photographic Research Association, which was the first Research Association to be formed under the Department of Scientific and Industrial Research, completed its term of five years in May last. A thorough and searching investigation of the work accomplished has been made by the Department, which has also taken into consideration the researches which are either in progress or are contemplated, with the result that a further grant in aid for a period of years has been promised. Although the financial position of the photographic industry, which is comparatively a small one, is at present at a very low ebb, it is very satisfactory to note that the leaders of the industry are so convinced of the valuable work done by the Research Association, and of the good results which are likely to accrue, that it has been decided to carry on its operations.
The Association has had to contend with considerable difficulties during its first five years, but, under the directorship of Dr. Slater Price, it has now a wellestablished reputation not only in this country, but also in Europe and America. A number of papers dealing with fundamental principles have been authorised for publication in the various scientific journals.

The Maidstone Museum has set a good example to other provincial institutions of this class by issuing a set of post-cards, published at $I \frac{1}{2} d$. each, illustrating its prehistoric collections. These include a clay bowl attributed to the Bronze Age; palæoliths of the Chellean period; a group of eoliths; some neolithic flint implements-all found in the vicinity. The series also includes a set of good examples of Roman glass.

\title{
Our Astronomical Column.
}

D'Arrest's Comet.-MM. Dubiago and Lexin continue the search ephemeris of this comet (for Greenwich Noon) : they use practically the same elements as those deduced by Mr. F. R. Cripps. There is still a prospect of finding the comet, as the greatest surface brightness is not attained until September 12; but the object is in considerable south declination in September and October.

\begin{tabular}{|c|c|c|c|c|c|}
\hline$A$ & $\begin{array}{c}\text { R.A. } \\
\text { h. } \\
\text { I7 } \\
\text { m. }\end{array}$ & $\begin{array}{l}\text { S. Decl. } \\
9^{\circ} 8^{\prime}\end{array}$ & & h.A. & S. Decl. \\
\hline 29. & $17 \times 7.5$ & II 49 & 13. & I7 57.9 & 1922 \\
\hline Sept. 3 . & I7 29.7 & I4 26 & I8. & I 8 I 3.8 & 2 I 34 \\
\hline
\end{tabular}

The Shower of August Meteors.-Mr. W. F. Denning writes:- "The fine warm weather and absence of strong moonlight enabled these meteors to be well observed during the period from August 3-Ir.

"The display, however, up to the time of writing (August 12) has not been an abundant one, though a fair number of Perseids appeared each night, and the radiant showed its usual displacement to the eastnorth-east.

“ Mr. J. P. M. Prentice, at Stowmarket, recorded the flights of $25^{\circ}$ meteors up to August 9, and had recognised a number of the usual minor showers, including $a$ Capricornids, $\delta$ and $\gamma$ Aquarids, $\delta$ Cassiopeids, $\gamma$ and $\theta$ Cygnids, Sagittids, $\epsilon$ Taurids, $a-\beta$ Perseids, $\beta$ Piscids, and Lacertids. Mr. Prentice saw a splendid Perseid fireball on August 9, I2h. $32 \mathrm{~m}$. G.M.T., with an estimated magnitude greater than that of the full moon. The streak lasted 23 seconds, and its colour was bright blue surrounded by bright red.

"Mr. A. King watched the shower from Lincolnshire on and after August 3, and saw a fair number of Perseids. At Bristol some observations were made on August 4-II, during which period the Perseids were only moderately active. The brightest meteor seen at Bristol was a Cygnid on August II, 9.40 G.M.T. It was brighter than Jupiter, and traversed a short path from $289^{\circ}+66^{\circ}$ to $289^{\circ}+72^{\circ}$; it left a white streak for a second, across $\delta$ Draconis."

Prof. R. Schorr's " Eigenbewegungs-Lexicon," -Prof. Schorr, director of Bergedorf Observatory, Hamburg, has just brought out a very useful work of reference in the form of a comprehensive catalogue of practically all the known proper-motions of stars. It is arranged in zones of declination, $I^{\circ}$ wide, the designation of the stars being taken from the Durchmusterungs of Bonn, Cordoba, and the Cape. It is numbered by columns (two to a page) and there are 400 columns, each containing some fifty stars.
Only one determination is given of each motion, presumably the best available; the authorities are given in each case. The centennial motion is given to two decimals of a second of time in right ascension, and one decimal of a second of arc in declination; a few stars are given to one figure less than this.

To diminish cost the work was typewritten, and then multiplied by a mechanical process, the result being perfectly clear and legible. The price is fixed at thirty Swiss francs.

Already a first supplement has appeared, ,containing I 739 stars ; some of these, marked " !," are improved values for stars already in the Lexicon, but the majority are additional stars.

This is the second very useful work that Prof. Schorr has issued in a few months, his new reduction of Rümker's Hamburg Catalogue having lately appeared (NATURE, April 28, p. 564).

The Free Pendulum. - Mr. F. Hope-Jones delivered a lecture on this subject to the British Horological Institute on April I9, and it has lately been issued as a pamphlet. He lays stress on giving the pendulum that we rely on as primary time-keeper as little work to do as possible; his three desiderata are: (I) the maintaining impulse must be given at the zero (lowest) position; (2) it must only be given occasionally; and (3) there must be no other interference with the pendulum.

Mr. Hope-Jones states that this problem has been solved, quite independently, by five men in the last twenty-five years: Mr. Rudd in 1898 , Sir David Gill in 1904, Mr. Bartrum in I9I3, Father O'Leary, S.J., during the War, and Mr. W. H. Shortt, who has been at work since I9I r on the matter, his clock being installed at Edinburgh Observatory early in I922. The details of each of the five methods are briefly given, but the last is considered much the best. The fundamental pendulum, constructed of invar, is in an air-tight case, pressure $3.5 \mathrm{~cm}$., kept at constant temperature. It receives its impulse every half-minute, at the lowest position; the remontoire is worked by the slave-clock, which is synchronised by a " hit or miss" action to within o.or second. Two diagrams of the changes of weekly rate in periods of three months are given; the range of weekly rate is 0.02 second per week. Prof. Sampson notes that the clock is superior to the Riefler instrument, though that is a very fine clock.

A clock with uniform rate is of great importance in fundamental astronomy for the removal of the small systematic errors in right ascension; they have been greatly redurced, but not wholly removed.

$$
\text { NO. } 2807 \text {, vOL. I I } 2 \text { ] }
$$

